\title{
Surgical treatment of mitral stenosis
}

\author{
TADEUSZ J. OT T O ${ }^{1}$ \\ From Sully Hospital, Penarth, Glam.
}

The first mitral valvotomy in Sully Hospital was carried out in November 1950 (D.M.E.T.) and was successful. Subsequently mitral valvotomy was performed routinely from July 1952, and this paper includes all patients operated upon between July 1952 and July 1963 . The total number of surgical corrections of mitral stenosis is 565 .

Four hundred and seventy-seven valvotomies were performed in addition to 69 revalvotomies, seven valvotomies combined with aortic valvotomies, and three valvotomies combined with other cardiac operations. Nine valvotomies were attempted but for various reasons were not performed. Of the patients who underwent surgery in this series, 426 were women and 139 men (Table I). The youngest patient was a girl aged 13 years, and the oldest, a woman aged 59 years. The average age of the women was 37 years and the average age of the men 39 years.

T A B LE I

\begin{tabular}{c|c|c}
\hline Sex & No. & $\%$ \\
\hline Women & 426 & $75 \cdot 4$ \\
Men & 139 & $24 \cdot 6$ \\
\hline Total & 565 & 100 \\
\hline
\end{tabular}

\section{CLINICAL SYMPTOMS}

All patients have been divided into three groups: those with mild symptoms, that is, with symptoms manifested clinically but not leading to restrictions in everyday life; those with moderate symptoms whose life activity was diminished; and patients with severe symptoms causing total or partial disability. There were 20 men and 86 women with mild, 81 men and 267 women with moderate, and 38 men and 73 women with severe symptoms (Table II). Fifteen men and 43 women had pulmonary arterial hypertension. Sixty-three men $(45.3 \%)$ and 137 women $(32.1 \%)$ had atrial filbrillation; the remainder were in sinus rhythm.

\footnotetext{
1 Present address : II Surgical Clinic, Medical Academy, Warsaw
}

TABLE I I

\begin{tabular}{|c|c|c|c|c|c|c|}
\hline \multirow{2}{*}{ Symptoms } & \multicolumn{2}{|c|}{ Men } & \multicolumn{2}{|c|}{ Women } & \multicolumn{2}{|c|}{ Total } \\
\hline & No. & $\%$ & No. & $\%$ & No. & $\%$ \\
\hline \multirow[t]{2}{*}{$\begin{array}{l}\text { Mild } \\
\text { Moderate } \\
\text { Severe } \\
\text { Pulmonary artery } \\
\text { hypertension }\end{array}$} & $\begin{array}{l}20 \\
81 \\
38\end{array}$ & $\begin{array}{l}14 \cdot 3 \\
58 \cdot 4 \\
27 \cdot 3\end{array}$ & $\begin{array}{r}86 \\
267 \\
73\end{array}$ & $\begin{array}{l}20 \cdot 2 \\
62 \cdot 7 \\
17 \cdot 1\end{array}$ & $\begin{array}{l}106 \\
348 \\
111\end{array}$ & $\begin{array}{l}18.7 \\
61.7 \\
19.6\end{array}$ \\
\hline & 15 & $10 \cdot 4$ & 43 & $10 \cdot 1$ & 58 & $10 \cdot 2$ \\
\hline
\end{tabular}

Thirty patients $(5.3 \%)$, including nine men and 21 women, gave a history of hemiplegia, and one man and two women gave a history of peripheral embolism. Of these, in only one patient was clot found in the atrium during operation, and in 11 patients the valve was calcified.

CO-EXISTING DISEASE Forty-nine patients had other cardiac lesions: 16 had aortic stenosis, 20 aortic incompetence, and 13 tricuspid valve lesions. Eighteen men and 26 women had clinical symptoms of co-existing mitral incompetence.

Eleven patients had pulmonary lesions: two of them had carcinoma (which was resected at the time of valvotomy), one had bronchial asthma, two had pneumoconiosis, four had chronic bronchitis, and two had bronchiectasis (which was resected).

PREGNANCY Six pregnant women, aged 24 to 35 years, were operated upon, all of whom had mild or moderate symptoms which worsened during pregnancy. In five patients operations took place during the first five months of pregnancy, and except in one case the results were very good. One woman, whose symptoms increased rapidly and could not have been controlled by other means, was operated upon in the seventh month of pregnancy. The result was also good.

\section{AETIOLOGY}

One hundred and twenty women and 56 men gave a history of rheumatic fever (Table III). The youngest age at which rheumatic fever occurred 
TABLE III

\begin{tabular}{|c|c|c|c|c|c|c|c|c|c|c|}
\hline \multirow{2}{*}{ History } & \multicolumn{4}{|c|}{ Men } & \multicolumn{4}{|c|}{ Women } & \multicolumn{2}{|c|}{ Total } \\
\hline & No. & $\%$ & Age (yr & & No. & $\%$ & Age (yr & & No. & $\%$ \\
\hline Rheumatic fever & 56 & $40 \cdot 2$ & $\begin{array}{l}\text { Youngest } \\
\text { Oldest } \\
\text { Average }\end{array}$ & $\begin{array}{r}2 \\
40 \\
13\end{array}$ & 120 & 25.8 & $\begin{array}{l}\text { Youngest } \\
\text { Oldest } \\
\text { Average }\end{array}$ & $\begin{array}{r}2 \\
34 \\
12\end{array}$ & 176 & $31 \cdot 1$ \\
\hline Chorea & 14 & $10 \cdot 1$ & $\begin{array}{l}\text { Youngest } \\
\text { Oldest } \\
\text { Average }\end{array}$ & $\begin{array}{r}3 \\
27 \\
11\end{array}$ & 73 & $17 \cdot 1$ & $\begin{array}{l}\text { Youngest } \\
\text { Oldest } \\
\text { Average }\end{array}$ & $\begin{array}{r}2 \\
19 \\
10\end{array}$ & 87 & 15.4 \\
\hline
\end{tabular}

The percentage in sexes relates to the total number of patients of that sex, and the total percentage relates to the total number of patients.

among the men was 2 years, the oldest 40 years, and the average age 13 years. The corresponding ages in women were 2 and 34 years, and average age 12 years. Thirty-two patients had more than one rheumatic episode.

Seventy-three women and 14 men suffered from chorea. The youngest age at which this occurred among women was 2 years, and among men 3 years; the oldest ages were 19 and 27 years respectively. The average age in women was 10 years, and in men 11 years.

Sixty-eight patients had a history of other diseases (tonsillitis), and in the remainder no definite aetiological factor was established.

\section{FINDINGS DURING OPERATION}

According to the size of the mitral orifice, as estimated by the surgeon during exploration of the valve, all patients have been divided into four groups (Harley, 1960). There were 283 patients with severe stenosis, 232 with considerable, and 36 with moderate stenosis. Five patients had normal or almost normal mitral orifices (Table IV).

In 58 patients regurgitation was felt above the mitral valve, but only in $11(20 \%)$ was this of haemodynamic significance. In 16 patients aortic stenosis was found, and in $\mathbf{1 8}$ aortic incompetence.

\section{TABLE IV}

\begin{tabular}{l|c|c}
\hline \multicolumn{1}{c|}{ Mitral Valve } & $\begin{array}{c}\text { No. of } \\
\text { Cases }\end{array}$ & $\%$ \\
\hline $\begin{array}{l}\text { Severe stenosis of orifice, } 1.25 \times 0.75 \mathrm{~cm} . \\
\text { or smaller }\end{array}$ & 283 & 50.9 \\
$\begin{array}{l}\text { Considerable stenosis of orifice, } 1.75 \times 1.0 \\
\text { cm. }\end{array}$ & 232 & 41.8 \\
$\begin{array}{l}\text { Moderate stenosis of orifice, approx.2.0-2.5 } \\
\times 1 \cdot 0-1 \cdot 5 \text { cm. }\end{array}$ & 36 & 6.4 \\
$\begin{array}{l}\text { Normal or almost normal } \\
\text { Regurgitation }\end{array}$ & 5 & 0.9 \\
\hline Calcified cusps or commissures & 141 & 10.4 \\
\hline in atrium & in appendage & 25.3 \\
\hline Clots & 10 & 1.7 \\
\hline
\end{tabular}

There were 141 calcified valves. Calcification was also found in the atrial wall in four patients, and in the appendage in one. Among 141 patients with calcified valves, 11 had had cerebral or peripheral emboli $(7.8 \%)$.

Clot in the appendage was found in 10 patients, and clot in the atrium in 29 patients. Seven of these 39 patients were not fibrillating.

\section{SURGICAL TECHNIQUE}

The operations performed upon these patients can be divider into four groups according to the surgical technique that was used:

1. Split performed with finger-128 cases (23.1\%).

2. Split performed with finger and knife- -45 cases $(8.0 \%)$.

3. Split performed with Tubbs' dilator inserted via the atrium-220 cases $(39.6 \%)$.

4. Split performed with Tubbs' dilator inserted via the ventricle-163 cases $(29.3 \%)$.

Most of these operations carried out in the years 1952 to 1955 belong to the first and second groups. Later the 'finger' and 'finger and knife' were the techniques of choice; 39 valvotomies were done with the finger and 15 with the knife (also some by other techniques). A Tubbs' dilator passed through the atrium was used on 166 occasions; the transventricular route was used on 108 occasions. A small number of valvotomies were done through the left ventricle or with the finger through the atrium.

The surgical approach to the heart for instrumental valvotomies via the atrium was achieved by posterolateral thoracotomy through the fourth interspace. For digital valvotomies, an anterolateral thoracotomy through the fifth intercostal space was used, and the patient was rotated backwards about $45^{\circ}$. A similar exposure was used for transventricular valvotomies. 


\section{SURGICAL RESULTS}

The results of valvotomy estimated by the surgeons during operation are given in Table V.

In 197 patients, considered as 'very good' results, a full split of both commissures was achieved. In 138, considered as 'good', an incomplete but sufficient split was achieved; this means that a total split of one commissure was obtained with partial but beyond 'critical area' (Baker, Brock, and Campbell, 1955) split of the other, or subtotal split of both commissures (beyond critical areas). The split was considered 'sufficient' from a haemodynamic rather than an anatomical point of view. In 152 patients the

TABLE V

\begin{tabular}{l|r|r}
\hline \multicolumn{1}{c|}{$\begin{array}{c}\text { Result Estimated by Surgeon after } \\
\text { Valvotomy }\end{array}$} & $\begin{array}{c}\text { No. of } \\
\text { Cases }\end{array}$ & $\%$ \\
\hline Very good & 197 & $34 \cdot 9$ \\
Good + regurgitation & 138 & $24 \cdot 4$ \\
Mooderate & 152 & 26.9 \\
Bad + regurgitation & 37 & 6.5 \\
Bad rad & 13 & $2 \cdot 3$ \\
Valvotomy abandoned & 9 & 3.4 \\
& & 1.6 \\
\hline
\end{tabular}

result was 'good + regurgitation', by which a full or sufficient split, with regurgitation of no haemodynamic or small haemodynamic significance, was obtained. In 37 patients the result was 'moderate', that is, some correction of the stenosis was obtained and relief of symptoms was expected. In 13 patients, called 'bad' results, the split was not sufficient to relieve symptoms, and in 19 classified as 'bad + regurgitation' serious regurgitation was created. Operation was abandoned in nine patients, in six because of fresh clot in the atrium, in two because of technical difficulties, and in one because of predominant incompetence.

\section{SURGICAL COMPLICATIONS}

POST-OPERATIVE INCOMPETENCE In 171 patients $(30.7 \%)$ incompetence was observed after valvotomy. The number with incompetence in relation to the number of operations performed

T A B L E V I

\begin{tabular}{|c|c|c|c|c|}
\hline \multirow[b]{2}{*}{ Patients } & \multirow[b]{2}{*}{$\begin{array}{c}\text { Digital } \\
\text { Valvotomy }\end{array}$} & \multirow[b]{2}{*}{$\begin{array}{c}\text { Digital } \\
\text { Valvotomy } \\
\text { with Knife }\end{array}$} & \multicolumn{2}{|c|}{ Tubbs' Dilator } \\
\hline & & & $\begin{array}{l}\text { Trans-atrial } \\
\text { Approach }\end{array}$ & $\begin{array}{c}\text { Trans- } \\
\text { ventricular } \\
\text { Approach }\end{array}$ \\
\hline No. & $\begin{array}{l}27 \\
21 \cdot 0\end{array}$ & $\begin{array}{l}13 \\
28 \cdot 8\end{array}$ & $\begin{array}{l}74 \\
33 \cdot 6\end{array}$ & $\begin{array}{l}57 \\
34.9\end{array}$ \\
\hline
\end{tabular}

by various surgical techniques is shown in Table VI.

In 35 of these 171 patients (19.8\%) incompetence existed before valvotomy and was increased or remained unchanged. In 23 valvotomy resulted in the disappearance of existing incompetence. Sixtythree valves $(38 \%)$ were calcified. Ninety-eight valves $(42.2 \%)$ were neither incompetent nor calcified, and no other factor but surgery alone resulted in incompetence.

Haemorrhage from the atrium or ventricle due to surgical damage was the complication of greatest significance and occurred in 38 patients. These were divided according to the various techniques, and the percentage was calculated in ralation to the number of operations performed by each technique (Table VII).

T A B L E V I I

\begin{tabular}{|c|c|c|c|c|}
\hline \multirow[b]{2}{*}{$\begin{array}{c}\text { Haemorr- } \\
\text { hage }\end{array}$} & \multirow[b]{2}{*}{$\begin{array}{c}\text { Digital } \\
\text { Valvotomy }\end{array}$} & \multirow[b]{2}{*}{$\begin{array}{c}\text { Digital } \\
\text { Valvotomy } \\
\text { with Knife }\end{array}$} & \multicolumn{2}{|c|}{ Tubbs' Dilator } \\
\hline & & & $\begin{array}{c}\text { Trans-atrial } \\
\text { Approach }\end{array}$ & $\begin{array}{c}\text { Trans- } \\
\text { ventricular } \\
\text { Approach }\end{array}$ \\
\hline Atrial & $\begin{array}{c}18 \\
(13.0 \%)\end{array}$ & $(2 \cdot 2 \%)$ & $\begin{array}{c}13 \\
(5.9 \%)\end{array}$ & 二 \\
\hline $\begin{array}{l}\text { Ventri- } \\
\text { cular }\end{array}$ & - & - & $(0.45 \%)$ & $(3.0 \%)$ \\
\hline
\end{tabular}

Some of these haemorrhages were small. and easily controllable. Three, however, were serious and resulted in the death of the patient in the operating theatre.

Cerebral embolism caused by valvotomy occurred in 10 patients $(0.17 \%)$ : seven of these died in the early post-operative phase and three recovered completely. Six patients had a peripheral embolism, including four of the femoral artery, all of which were treated surgically. Removal of the embolus in three patients resulted in a complete recovery, and one patient died. Two patients had an embolism of the mesenteric artery, and both died.

Of the 16 patients who had a post-operative embolism, in only five was clot found during operation, giving an approximate percentage of $33.3 \%$. In seven, calcification of the mitral valve was present $(43.7 \%)$. In four patients $(33 \%)$ no cause of subsequent embolism was found during operation.

\section{MORTALITY}

Four patients died in the theatre during or immediately after valvotomy. Three of these deaths were due to surgical haemorrhage, and one 
TABLE VIII

\begin{tabular}{|c|c|c|c|c|c|c|c|c|c|c|c|}
\hline \multirow[b]{2}{*}{ Time of Death } & \multirow[b]{2}{*}{ 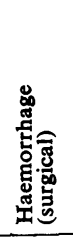 } & \multicolumn{2}{|c|}{ Damage to } & \multicolumn{3}{|c|}{ Embolism } & \multirow{2}{*}{ 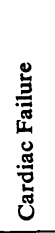 } & \multirow[b]{2}{*}{ 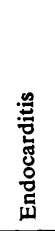 } & \multirow[b]{2}{*}{ 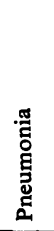 } & \multirow[b]{2}{*}{$\begin{array}{l}\text { Total No. } \\
\text { of Cases }\end{array}$} & \multirow[b]{2}{*}{$\%$} \\
\hline & & 莺 & $\frac{\sum^{\frac{D}{\pi}}}{>}$ & $\begin{array}{l}\overline{5} \\
\text { हूँ } \\
\text { U⿺ }\end{array}$ & 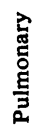 & 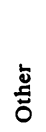 & & & & & \\
\hline $\begin{array}{l}\text { In theatre } \\
\text { In early post-operative course }\end{array}$ & 3 & 1 & $\overline{6}$ & 7 & $\overline{2}$ & $\overline{3}$ & $\overline{5}$ & $\overline{-}$ & $\overline{1}$ & $\begin{array}{r}4 \\
24\end{array}$ & $\begin{array}{l}0.7 \\
4 \cdot 2\end{array}$ \\
\hline \multirow{2}{*}{ Late } & \multirow{2}{*}{-} & \multirow{2}{*}{-} & \multirow{2}{*}{14} & \multirow{2}{*}{3} & \multirow{2}{*}{1} & \multirow{2}{*}{1} & \multirow{2}{*}{4} & \multirow{2}{*}{2} & \multirow{2}{*}{3} & Cardiac reasons 2 & 3.5 \\
\hline & & & & & & & & & & Others & 1.06 \\
\hline
\end{tabular}

was due to rupture of the inter-atrial septum. Twenty-four patients died during the post-operative course, 11 due to cerebral or peripheral embolism, six to mitral incompetence, two to pulmonary embolism, one to pneumonia, and four as a result of cardiac failure (all four had pulmonary arterial hypertension before operation). This gives a hospital mortality of $4.9 \%$. Twenty patients died from a cardiac cause within three years of their operations (see Table VIII).

\section{RE-VALVOTOMIES}

The total number of re-valvotomies carried out at Sully Hospital was 69 (12\%). Among these were 38 patients who had had previous operations performed in other hospitals.

Sixty patients have been taken into consideration, 31 operated on previously at Sully, and others whose notes were available. The shortest interval between valvotomy and re-valvotomy was one year, the longest 11 years, averaging 5 years 4 months. In three patients of $60(5.0 \%)$ during previous valvotomy a very good split had been obtained, in $45(75 \%)$ a good split, and in 12 patients $(20 \%)$ the surgical result following the first valvotomy was not satisfactory.

Three patients had three valvotomies performed, the intervals between the first and second and second and third valvotomy being as follows: (1) 1 year ; 7 years, (2) 6 years ; 1 year, (3) 1 year ; 7 years.

All re-valvotomies were performed in the same manner as previous valvotomies, the only difference being that the valve was approached through the atrium and not through the appendage.

\section{FINAL CLINICAL RESULTS}

Two hundred and eighty-nine patients were followed up in the out-patients clinic for more than two years. The longest time of observation was 10 years, the average 3 years 7 months.

The results were graded as follows: very good -patients without evident clinical symptoms; good-patients with some clinical symptoms but no restriction to everyday life, and not requiring revalvotomy at present ; moderate-patients requiring re-valvotomy and able to tolerate it; bad-all patients who are worse than before valvotomy; some of these are unable to tolerate re-valvotomy (Table IX). The number of deaths in this table applies to patients who died during an observation period longer than two years.

T A B LE I X

\begin{tabular}{l|c|c}
\hline \multicolumn{1}{c|}{ Result } & Number & $\%$ \\
\hline Very good & 128 & $49 \cdot 6$ \\
Good & 61 & 23.7 \\
Moderate & 32 & 12.7 \\
Bad & 23 & 8.9 \\
Died & 14 & $5 \cdot 4$ \\
\hline
\end{tabular}

Some of the 23 patients with bad results underwent subsequent re-valvotomy, others refused operation or their condition was too grave to tolerate surgery. Others, who had re-valvotomy, come under the group of 'moderate' results.

The clinical results of patients who had had re-valvotomy and who were observed subsequently for at least two years are grouped in the same manner (Table $\mathrm{X}$ ).

The clinical results in 156 patients with surgically created incompetence observed for at

TABLE X

\begin{tabular}{l|c|c}
\hline \multicolumn{1}{c|}{ Result } & Number & $\%$ \\
\hline Very good & 14 & $45 \cdot 1$ \\
Good & 9 & $29 \cdot 0$ \\
Moderate & 4 & $12 \cdot 9$ \\
Bad & 2 & $6 \cdot 4$ \\
Died & 2 & $6 \cdot 4$ \\
\hline
\end{tabular}


TABLE X I

\begin{tabular}{l|c|c|c}
\hline $\begin{array}{l}\text { Very Good } \\
\text { and Good }\end{array}$ & Moderate & Bad & Died \\
\hline $106(67 \cdot 8 \%)$ & $21(13 \cdot 8 \%)$ & $9(5 \cdot 4 \%)$ & $20(13 \%)$ \\
\hline
\end{tabular}

least two years are of interest (Table XI). There were 106 patients without any evident clinical symptoms, 21 patients with clinical symptoms not restricting everyday life, and nine patients badly handicapped ; 20 patients died.

It is also interesting to observe the clinical results in 19 patients in whom, according to surgical estimation, gross incompetence was created (Table XII).

T A B LE X I I

\begin{tabular}{c|c|c|c}
\hline Satisfactory & Moderate & Bad & Died \\
\hline $4(21 \%)$ & $5(26 \cdot 3 \%)$ & $1(5 \cdot 3 \%)$ & $9(47 \cdot 3 \%)$ \\
\hline
\end{tabular}

Gross incompetence in these patients was created either by damage to the cusps, due to an irregular split out of the line of commissures, or by rupture of the chordae tendineae.

Finally, I would like to compare the results as estimated by the surgeon during operation with the clinical findings. This comparison concerns 244 patients under observation for at least two years (Table XIII).

TABLE XIII

\begin{tabular}{|c|c|c|c|c|}
\hline \multirow{2}{*}{$\begin{array}{c}\text { Surgical } \\
\text { Result }\end{array}$} & \multirow{2}{*}{ No. } & \multicolumn{3}{|c|}{ Clinical Results } \\
\hline & & $\begin{array}{l}\text { Very good } \\
\text { and good }\end{array}$ & Moderate & Bad \\
\hline $\begin{array}{l}\text { Very good and good } \\
\text { Moderate } \\
\text { Bad }\end{array}$ & $\begin{array}{r}208 \\
20 \\
16\end{array}$ & $\begin{array}{l}175(84 \cdot 1 \%) \\
11(55 \cdot 0 \%) \\
3(18 \cdot 7 \%)\end{array}$ & $\begin{array}{l}20(9.6 \%) \\
6(30.0 \%) \\
6(37.5 \%)\end{array}$ & $\begin{array}{l}13(6 \cdot 2 \%) \\
3(15 \cdot 0 \%) \\
7(43.7 \%)\end{array}$ \\
\hline
\end{tabular}

DISCUSSION

The presented material does not differ from that published by other authors. However, the female to male ratio is $3: 1$, whereas other publications (Dubost, Blondeau, and Piwnica, 1962; Wood, 1956) give it as $4: 1$. The average age of Wood's patients was 37 years ; in our patients the average age was 37 for women but 39 for men. The youngest patient, who was 13 , and the oldest, who was 59 , are within limits quoted by other authors (Manteuffel-Szoege, 1961 ; Scannell, Burke, Saidi, and Turner, 1960). The results obtained in this series on very young as well as on very old patients are as good as those obtained in patients of intermediate age.

In Wood's statistics (Wood, 1954 and 1956) rheumatic fever or chorea was detected as an aetiological factor of mitral stenosis in $60 \%$ of patients. De Jesus, Breneman, and Keyes (1962) give a figure of $65 \%$. In this series, in only $46.5 \%$ was a history of rheumatic fever or chorea obtained (31.1\% rheumatic fever ; $15.4 \%$ chorea).

The majority of patients in this series $(61.7 \%)$, both women and men, had moderate pre-operative symptoms. Operations performed for mild symptoms were more common among the women patients, whereas operations for severe symptoms were more common among the men. This seems to be due rather to psychological differences between the sexes than to different manifestations of the disease. Fifty-eight of our patients had pulmonary arterial hypertension, which in the majority was diagnosed on clinical symptoms, electrocardiogram, and radiological features (Aber, Campbell, and Meecham, 1963 ; Manteuffel-Szoege, 1961). In some of these patients cardiac catheterization was carried out and confirmed the diagnosis. Ten of these patients died, which gives a hospital mortality of $17.2 \%$ compared with $3.5 \%$ for non-hypertensive patients. This is a high mortality but is lower than that given by Emanuel for mitral stenosis with a high pulmonary vascular resistance, namely $26 \%$ (Emanuel, 1963); but Emanuel took a high critical level (10 units) whereas in our series the average pulmonary vascular resistance was 7 units. Twenty-three patients with pulmonary arterial hypertension, who during at least two years of observation were considered clinically as 'very good' or 'good' results, seem to prove that pulmonary vascular resistance is in some patients reversible.

In 32 of 200 patients who were fibrillating, a clot was found in the atrium or appendage. This gives a figure of $16 \%$, whereas in non-fibrillating patients a clot was found in $2.6 \%$. Hospital mortality for the fibrillating patients was as high as $12 \%$ as compared with $1.5 \%$ for those not fibrillating. This confirms the common opinion as to the importance of atrial fibrillation in the prognosis of surgery for mitral stenosis (De Jesus et al., 1962 ; Scannell et al., 1960 ; Wood, 1954 and 1956). All fibrillating patients were on anticoagulant therapy for at least two weeks before surgery; this precaution probably accounts for the embolic rate for patients with clot in the atrium or appendage of only $2.5 \%$. This fact does not diminish the significance of the presence of clots, for in six cases the operation had to be 
abandoned because of fresh, extensive clot in the atrium. Altogether we found clots in $6.8 \%$ of patients, which is less than $11 \%$ in Dubost material (Dubost et al., 1962) or $22 \%$ in Wood's (Wood, 1956). Only one of these patients $(2.6 \%)$ gave a history of hemiplegia.

Estimation of the size of the mitral orifice during closed mitral valvotomy is subjective and not very important, for the degree of stenosis does not influence the ease of performing adequate mitral valvotomy. However, our findings of $50.9 \%$ of severe stenosis, $41.8 \%$ of considerable stenosis, and only $0.9 \%$ of normal or almost normal orifices seem to indicate that the selection of patients for valvotomy in this series was good.

Calcification of the valve was found in $25.3 \%$ of patients, which is slightly less than $29 \%$ given by Logan, Lowther, and Turner (1962), or $28 \%$ given by Wood (1954). The embolic rate among patients with calcified valves was $7.8 \%$ as compared with $5.2 \%$ for normal valves; therefore in patients with calcified valves operated upon recently special precautions were taken to protect the brain from embolism. The best results were obtained in patients who had aortic branches dissected and completely occluded, as we did not observe any cerebral embolism in these. The relation between calcified valves and the occurrence of traumatic incompetence was obvious in this material; as mentioned before, $38 \%$ of patients with iatrogenic incompetence had calcified valves.

Pre-operative incompetence was diagnosed during exploration of the mitral valve in $10.4 \%$ of all patients. This is less than $24 \%$ cited by Wood (1954) or $16 \%$ cited by Dubost et al. (1962). In $24.1 \%$ of patients incompetence was not manifest clinically and was not diagnosed before the operation. The disappearance of incompetence after mitral valvotomy observed in this material might seem doubtful. However, Dubost also observed a similar phenomenon in $5 \%$ of patients.

Post-operative incompetence has been noticed in this series in $30.3 \%$ of patients (approximately as often as reported by Nauta and Hartman (1962) ). This is a higher percentage than $17 \%$ cited by Logan and Turner (1959) or $16 \%$ cited by Björk and Malers (1963). However, 35 patients who had mitral regurgitation before the operation, which in some remained unchanged, are included here. Taking into consideration patients who did not have pre-operative incompetence, traumatic incompetence was present in $17.3 \%$ of patients with non-calcified valves and in $44.7 \%$ of patients with calcification of the valve. In contra-distinction to other authors (Dubost et al., 1962; Nauta and Hartman, 1962), the lowest rate of incompetence was observed after digital valvotomy (Table VI).

As is evident from Tables XI and XII, in the majority of patients post-operative incompetence was of little haemodynamic significance, and the number of patients with 'very good' and 'good' clinical results was quite high. Even among patients who had severe incompetence, some clinically satisfactory results were observed. The high mortality rate among these patients seems to indicate that serious incompetence leads to rapid cardiac failure and death, whereas incompetence of small degree does not handicap patients very much. Considering that an inadequate valvotomy increases the occurrence of restenosis (Baker et al., 1955; Belcher, 1958 and 1960), the author believes that it is better to have a complete valvotomy with some incompetence than an incomplete one without any. This is a matter of opinion.

In this series re-stenosis of the mitral valve appeared in 12 patients in whom the surgical result of the primary valvotomy was not satisfactory $(20.0 \%)$, and the re-stenosis in these cases was clearly 'false'.

In 45 patients $(75 \%)$ who underwent re-valvotomy, the result of primary valvotomy was 'good' which, according to the classification used in this paper, did not mean an 'ideal' valvotomy ; therefore re-stenosis could have occurred as the result of lack of full mobility of the cusps or the continued existence of a partial fusion of the commissures. In three patients, however, the result at primary valvotomy was estimated as 'very good'. In one of these, aged 15 years, after three symptom-free years a second episode of acute rheumatic fever occurred, which resulted in re-stenosis of the mitral valve.

Our results confirm the opinion that re-stenosis of the mitral valve usually occurs after inadequate valvotomy, whether this be due to inadequate surgery or to the condition of the valve.

Re-valvotomy was usually performed within a few months of the re-appearance of symptoms of mitral block. The average time between valvotomy and re-valvotomy (5 years 4 months) was longer than that quoted by other authors (Belcher, 1960 ; Dubost et al., 1962; De Jesus et al., 1962; Scannell et al., 1960). Clinical results after re-valvotomies were as good as those after the primary operations (Tables IX and $\mathbf{X}$ ).

The presented material provides an opportunity for comparing various surgical techniques, especially as all techniques have been contemporarily used and on the same selection of patients. The only reservation is that on several 
occasions valvotomy could not have been performed digitally and was completed with the knife. Therefore the latter should be considered rather as a completion of digital valvotomy, and the results should be read together.

Instrumental valvotomies via the atrium were carried out with the use of Tubbs' dilator. Among several publications concerning this approach to the mitral valve (Dubost et al., 1962 ; Edwards, 1962 ; Logan and Turner, 1959 ; Logan, 1957) I found no mention of the use of Tubbs' dilator. In the hands of one of our surgeons (D.M.E.T.) this instrument proved to be very satisfactory and, due to its small diameter, in some respects even better than other dilators used for the trans-atrial approach. However, in less experienced hands this dilator was very traumatic and more dangerous than Dubost's instrument. For the transventricular route Tubbs' dilator was appreciated by all our surgeons. As reported by others (Logan and Turner, 1959; Wilcken, 1960), transventricular valvotomy was found to be relatively easy and enabled the blades of the dilator to be placed accurately in the mitral orifice. The advantage of instrumental valvotomies, both through the atrium and through the ventricle. and the ease of obtaining a good split, especiallv in difficult ciases, were obvinus

However, as is evident from Table VI, digital valvotomy caused the lowest incidence of incompetence. Even if the results of digital valvotomy with the use of the knife are included, this number is still smaller than for instrumental valvotomies. Also most of the patients, in whom incompetence present before valvotomy disappeared afterwards, had digital valvotomy performed (H.R.S.H.). On the other hand, this technique resulted in atrial haemorrhage more frequently than any other.

The only conclusion which can be drawn from these facts is that the surgical technique does not play as important a role as personal experience, and the latter, plus the condition of the valve, greatly influence the result of valvotomy.

The surgical complications in the material presented here do not differ from those observed by other authors, and the final clinical results, as presented in Table IX, look satisfactory by comparison with other statistics. There is a definite relation between the quality of the operation as estimated by the surgeon and the results observed in the follow-up clinic.

\section{SUMMARY}

Five hundred and sixty-five patients who had a mitral valvotomy performed at Sully Hospital are presented. The results obtained, with particular reference to traumatic incompetence, re-stenosis and various surgical techniques, are discussed.

I would like to thank Mr. D. M. E. Thomas, Mr. H. R. S. Harley, and Mr. T. H. L. Rosser for permission to publish their results, Mr. Harley for checking this paper, Miss Margaret Herbert for her help in segregating material, and Miss Patricia Morse for secretarial help.

\section{RE FERENCES}

Aber, C. P., Campbell, J. A., and Meecham, J. (1963). Arterial patterns in mitral stenosis. Brit. Heart J., 25, 109.

Baker, C., Brock, R., and Campbell, M. (1955). Mitral valvotomy, A follow up of 45 patients for three years and over. Brit. med. J., 2,983

Belcher, J. R., (1958). Restenosis of the mitral valve. Brit. Heart J., $20,76$.

(1960). Restenosis of the mitral valve. An account of fifty second operations. Lancet, $1,181$.

Björk, V. O., and Malers, E. (1963). Traumatic mitral insufficiency following transventricular dilatation for mitral stenosis. $J$. thorac. cardiovasc. Surg., 46, 84.

Dubost, C., Blondeau, P., and Piwnica, A. (1962). Instrumental dilataion using the transatrial approach in the treatment of mitral stenosis. A survey of 1,000 cases, Ibia. 44, 392 .

Edwards, F. R. (1962). Instrumental transatrial mitral valvotomy. Thorax, 17 271.

Emanuel, R., (1963). Valvotomy in mitral stenosis with extreme pulmonary vascular resistance. Brit. Heart J., 25, 119.

Harley, H. R. S. (1960). Some aspects of the surgical treatment of mitral valve disease. In Modern Trends in Cardiac Surgery, Ed. Harley, H. R. S., p. 192. Butterworth, London.

De Jesus, J. R., Jr., Breneman, G. M., and Keyes, J. W. (1962). Recurrent stenosis of the mitral valve. Circulation, 25, 619.

Logan, A. (1957). The transventricular route for mitral valvulotomy. Kardiol. Pol., 1, 49.

Kowther, C. P., and Turner, R. IV. J. (1962). Reoperation for mitral stenosis. Lancet, 1, 443.

and Turner, R. (1959). Surgical treatment of mitral stenosis. Ibid., 2, 874.

Manteuffel-Szoege, L., (1961). Wybrane Zagadnienia Z Chirurgii Klatki Piersiowej. Warsaw.

Nauta, J., and Hartman, H. (1962). The use of instruments in commissurotomy for mitral stenosis. Thorax, 17, 85.

Scannell, J. G., Burke, J. F., Saidi, F., and Turner, J. D. (1960). Five years follow-up study of closed mitral valvulotomy. $J$. thorac. cardiovasc. Surg., $40,723$.

Wilcken, D. E. L. (1960). Mitral valvotomy and restenosis. Brit. med. J. 1.681 .

Wood, P. (1954), An appreciation of mitral stenosis. Ibid., 1, 1113. (1956). Diseases of the Heart and Circulation. 2nd ed. Eyte and Spottiswoode, London. 